Article

\title{
Serum Type XIX Collagen is Significantly Elevated in Non-Small Cell Lung Cancer: A Preliminary Study on Biomarker Potential
}

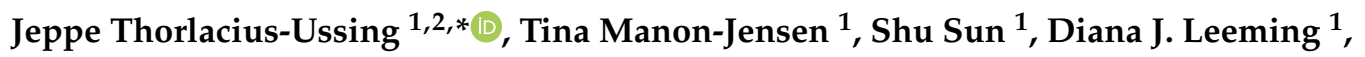 \\ Jannie M. Sand ${ }^{1}{ }^{\mathbb{D}}$, Morten Karsdal ${ }^{1}$ and Nicholas Willumsen ${ }^{1}$ \\ 1 Biomarkers and Research, Nordic Bioscience A/S, 2730 Herlev, Denmark; tmj@nordicbio.com (T.M.-J.); \\ ssu@nordicbio.com (S.S.); djl@nordicbio.com (D.J.L.); jsa@nordicbio.com (J.M.S.); mk@nordicbio.com (M.K.); \\ nwi@nordicbio.com (N.W.) \\ 2 Department of Biomedical Sciences, University of Copenhagen, 2200 Copenhagen, Denmark \\ * Correspondence: jtu@nordicbio.com
}

Received: 29 May 2020; Accepted: 5 June 2020; Published: 9 June 2020

check for updates

\begin{abstract}
Type XIX collagen is a poorly characterized collagen associated with the basement membrane. It is abnormally regulated during breast cancer progression and the NC1 (XIX) domain has anti-tumorigenic signaling properties. However, little is known about the biomarker potential of collagen XIX in cancer. In this study, we describe a competitive ELISA, named PRO-C19, targeting the C-terminus of collagen XIX using a monoclonal antibody. PRO-C19 was measured in serum of patients with a range of cancer types and was elevated in non-small cell lung cancer (NSCLC) $(p<0.0001)$, small cell lung cancer $(p=0.0081)$, breast $(p=0.0005)$ and ovarian cancer $(p<0.0001)$ compared to healthy controls. In a separate NSCLC cohort, PRO-C19 was elevated compared to controls when evaluating adenocarcinoma (AD) $(p=0.0003)$ and squamous cell carcinoma (SCC) $(p<0.0001)$ patients but was not elevated in chronic obstructive pulmonary disease patients. SCC also had higher PRO-C19 levels than AD ( $p=0.0457)$. PRO-C19 could discriminate between NSCLC and healthy controls (AUROC:0.749 and 0.826 for AD and SCC, respectively) and maintained discriminatory performance in patients of tumor stages I+II (AUROC:0.733 and 0.818 for AD and SCC, respectively). Lastly, we confirmed the elevated type XIX collagen levels using gene expression data from The Cancer Genome Atlas (TCGA) and Genotype-Tissue Expression (GTEx) initiatives. In conclusion, type XIX collagen is released into circulation and is significantly elevated in the serum of cancer patients and PRO-C19 shows promise as a cancer biomarker.
\end{abstract}

Keywords: collagen XIX; ECM; biomarker; serum; cancer; NSCLC; AD; SCC

\section{Introduction}

Lung cancer is the most commonly diagnosed cancer and is the leading cause of cancer death [1]. Non-small cell lung cancer (NSCLC) represents approximately $85 \%$ of all lung cancer cases, wherein adenocarcinoma (AD) and squamous cell carcinoma (SCC) are the most common subtypes [2,3]. The majority of lung cancer cases are diagnosed in later stages, resulting in a grim overall five-year survival rate of $19 \%$ [4]. However, for patients diagnosed in the localized stages, where most of the patients can benefit from surgical resection, the five-year survival rate is $56 \%$ [2,4]. Early detection is therefore one of the primary ways to improve survival for lung cancer patients.

The tumor microenvironment is intricately involved in the traditional cancer hallmarks that dictate tumor progression [5]. One of the major components of the tumor microenvironment is the extracellular matrix (ECM), the non-cellular part of tissues, which influences virtually all of these 
cancer hallmarks [6]. The most dominant proteins in the ECM are the collagens, of which there are 28 different types [7]. Our research group has previously demonstrated that collagens and other ECM proteins can be valuable as non-invasive biomarker tools in different cancer forms [8-17].

Type XIX collagen is a minor collagen that comprises three $\alpha 1$ chains forming a $400 \mathrm{kDa}$ homotrimer. Each chain comprises five collagenous triple helix domains interspersed with six non-collagenous domains. Based on its primary sequence, type XIX collagen belongs to the Fibril-Associated Collagen with Interrupted Triple helices family of collagens which mediate interactions between fibrillar collagens and other ECM components [18-20].

A description of expression and localization of type XIX collagen in the human lungs is lacking in the literature, but in other tissues localization is associated with the vascular-, neural-, muscularand some epithelial basement membrane zones (BMZ) [21]. Interestingly, protein staining of type XIX collagen in the epithelial BMZ of breast carcinoma is partially lost in localized ductal carcinoma and is completely absent in invasive carcinomas. This loss occurs earlier than the loss of type IV collagen and laminin, suggesting that decreased type XIX collagen levels is a result of the early stages of BMZ remodeling [22].

Similar to the release of matrikines from the NC1 domains of type IV, XV and XVIII collagens, the C-terminal NC1 domain of type XIX collagen can be cleaved off and released. The resulting peptide can inhibit the growth and angiogenesis of melanoma in vivo and inhibit invasiveness in vitro [23]. The NC1 domain is cleaved off by the plasmin protease and interacts with $\alpha \mathrm{v} \beta 3$ integrin to inhibit the FAK/PI3K/Akt/mTOR signaling pathway as well as inhibit GSK3 $\beta$ phosphorylation $[24,25]$.

In this study, we developed and validated an enzyme-linked immunosorbent assay (ELISA) to quantify the C-terminus of type XIX collagen in serum, named PRO-C19. We demonstrate the biological relevance and biomarker potential of the resulting assay in serum of cancer patients. We found that PRO-C19 was significantly elevated in the serum of several different cancer types. PRO-C19 could discriminate between NSCLC and healthy controls and showed promise as a biomarker for NSCLC.

\section{Results}

\subsection{PRO-C19 ELISA Development}

Specificity of the competitive ELISA, named PRO-C19, was assessed by the proficiency of peptides to compete for binding to the monoclonal antibody. Peptides that were tested included the standard calibrator peptide (SHAHQRTGGN), an elongated calibrator peptide (SHAHQRTGGNA), a truncated calibrator peptide (SHAHQRTGG), a nonsense peptide (GVAPGIGPGG) and a nonsense coater peptide (Biotin-GVAPGIGPGG). Only the standard peptide dose-dependently inhibited the signal (Figure 1). The non-sense coater peptide resulted in no detectable signal. In all, this indicates that the assay is specific to the SHAHQRTGGN epitope of type XIX collagen.

Technical validation of the PRO-C19 assay is summarized in Table 1. Linearity of dilution and parallelism was acceptable once serum samples were diluted 1:4, after which there was an average dilution recovery of $101.7 \%$ (Figure 2). Matrix accuracy in serum was acceptable with an average spiking recovery of $118.6 \%$ using the standard peptide spiked into human serum samples at a final dilution of 1:4. The influence of commonly interfering agents including hemoglobin, lipids and biotin was not observed. Inter-assay variation was $10.9 \%$ and intra-assay variation was $6.6 \%$. The measurement range was determined as 3.31-214.3 ng/mL and the lower limit of detection was $1.23 \mathrm{ng} / \mathrm{mL}$ and upper limit $443.5 \mathrm{ng} / \mathrm{mL}$. Analyte stability was acceptable for up to $24 \mathrm{~h}$ at $4{ }^{\circ} \mathrm{C}$ and up to $4 \mathrm{~h}$ at $20^{\circ} \mathrm{C}$. Freeze-thaw stability was acceptable for over 4 freeze-thaw cycles. 


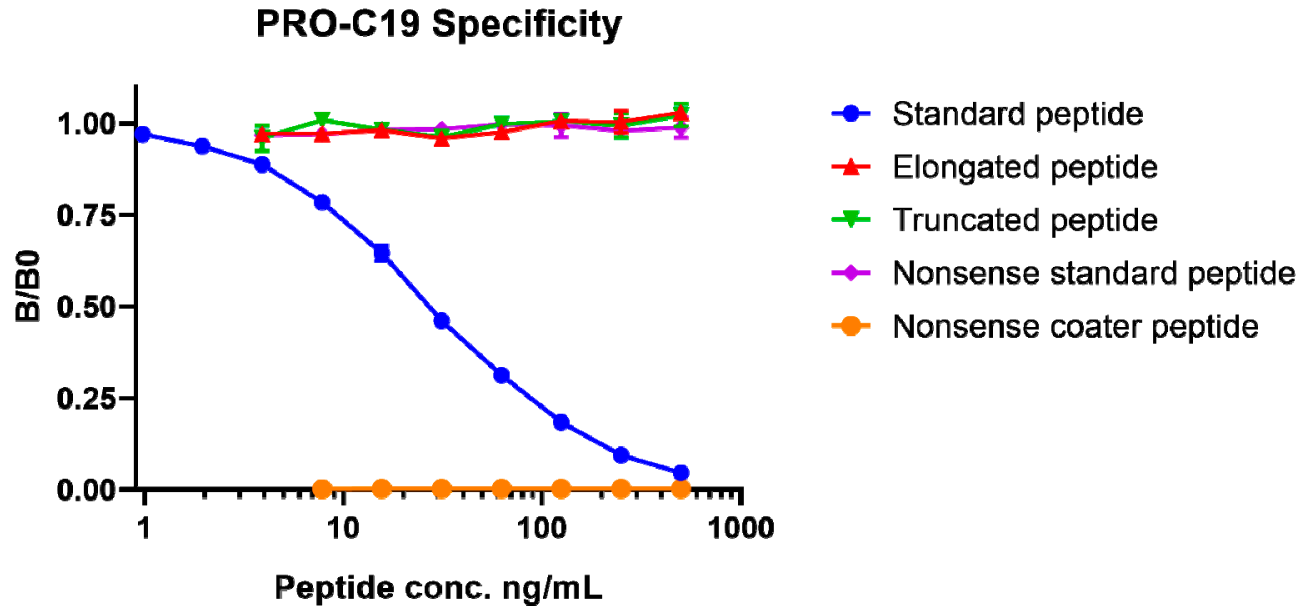

Figure 1. PRO-C19 assay specificity. Inhibition curve for the standard peptide (SHAHQRTGGN), elongated peptide (SHAHQRTGGNA), truncated peptide (SHAHQRTGG) as well as non-sense standard peptide (GVAPGIGPGG) and a non-sense coater peptide (Biotin-GVAPGIGPGG). Peptides were diluted twofold in series to evaluate their propensity to compete for antibody binding. Signal is shown as a fraction of the background absorbance (B0), corresponding to assay buffer, as a function of the peptide concentration on a logarithmic scale. Error bars indicate standard deviation from duplicate measurements.

Table 1. Summary of the technical validation of PRO-C19.

\begin{tabular}{cc}
\hline Test & Result \\
\hline IC50 & $29.5 \mathrm{ng} / \mathrm{mL}$ \\
Measurement range & $3.31-214 \mathrm{ng} / \mathrm{Ll}$ \\
Detection range & $1.23-443 \mathrm{ng} / \mathrm{L}$ \\
Minimum required dilution in human serum & $1: 4$ \\
Dilution recovery of human serum below $1: 4$ & $102 \%$ \\
Spiking recovery of peptide in serum & $119 \%$ \\
Interference hemoglobin, low/high conc. & $95.1 \% / 93.4 \%$ \\
Interference lipids, low/high conc. & $104 \% / 104 \%$ \\
Interference biotin, low/high conc. & $101 \% / 101 \%$ \\
Inter-assay variation & $10.9 \%$ \\
Intra-assay variation & $6.63 \%$ \\
Analyte stability (24 hrs $4{ }^{\circ} \mathrm{C} / 4$ hrs $\left.20{ }^{\circ} \mathrm{C}\right)$ & $85.3 \% / 82.3 \%$ \\
Freeze-thaw stability up to four cycles & $97.7 \%$ \\
\hline
\end{tabular}

\section{PRO-C19 Parallelism}

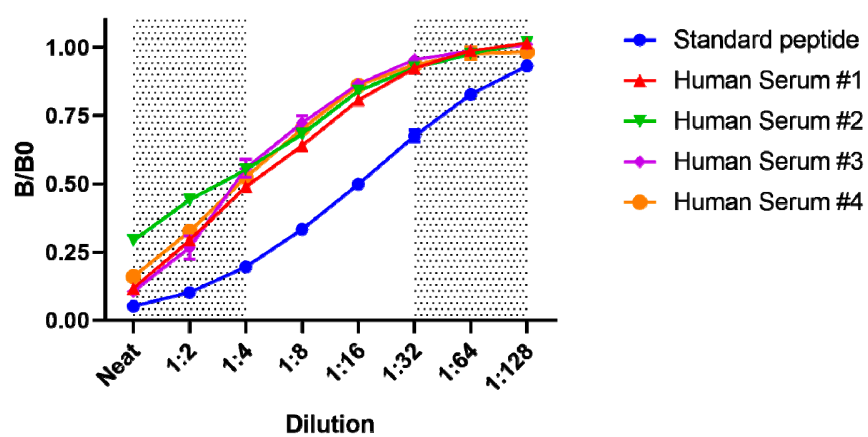

Figure 2. PRO-C19 parallelism. Inhibition curve for the standard peptide and human serum samples diluted twofold to assess linearity of dilution or parallelism. Signal is shown as a fraction of the background absorbance (B0), corresponding to assay buffer, as a function of the dilution steps. Error bars indicate standard deviation from duplicate measurements and greyed-out region indicates the limits of the linear range of the assay. 


\subsection{PRO-C19 in Serum of Cancer Patients (Cohort 1)}

As a first step to explore the usefulness of PRO-C19 in a cancer context, PRO-C19 was assessed in a cohort consisting of a range of cancer types including 12 breast cancer patients, 7 colon cancer patients, 9 gastric cancer patients, 6 melanoma patients, 11 NSCLC patients, 8 ovarian cancer patients, 2 pancreatic cancer patients, 13 prostate cancer patients, 7 small cell lung cancer (SCLC) patients as well as 38 healthy controls (Table 2). In the cancer group there was no significant association between PRO-C19 levels and age, BMI or smoking history. PRO-C19 levels were significantly elevated in NSCLC $(p<0.0001)$, SCLC $(p=0.0081)$, breast $(p=0.0005)$ and ovarian cancer $(p<0.0001)$ compared to healthy controls (Figure 3A). Although not significant, colon and pancreatic cancer groups also had higher mean PRO-C19 levels whereas gastric cancer had lower mean PRO-C19 levels as compared to healthy controls. With a cut-off of $63.3 \mathrm{ng} / \mathrm{mL}$, PRO-C19 could discriminate between healthy and NSCLC with an area under receiver operating characteristic (AUROC) of 0.995 with a corresponding sensitivity of $100 \%$ and specificity of $94.74 \%$ (Table 3). PRO-C19 could also discriminate between healthy and SCLC with an AUROC of 0.808 at a cut-off of $54.3 \mathrm{ng} / \mathrm{mL}$ with a corresponding sensitivity of $71.4 \%$ and specificity of $84.2 \%$. PRO-C19 could also discriminate between healthy and breast cancer with an AUROC of 0.814 at a cut-off of $41.85 \mathrm{ng} / \mathrm{mL}$ with a corresponding sensitivity of $75 \%$ and specificity of $78.9 \%$. Lastly, PRO-C19 could also discriminate between healthy and ovarian cancer with an AUROC of 0.839 at a cut-off of $60.31 \mathrm{ng} / \mathrm{mL}$ with a corresponding sensitivity of $75 \%$ and specificity of $92.1 \%$. Overall, although this cohort has its limitations, these results suggest that circulating levels of type XIX collagen are elevated in several different cancer types.

Table 2. Demographics of the cohorts.

\begin{tabular}{|c|c|c|c|c|c|}
\hline Cohort 1 & \multicolumn{2}{|c|}{ Healthy Controls $(n=38)$} & \multicolumn{2}{|c|}{ Cancers $(n=75)$} & $p$-Value \\
\hline $\begin{array}{c}\text { Age, } \\
\text { median } \\
(\min -m a x)\end{array}$ & \multicolumn{2}{|c|}{$71.5(60-82)$} & \multicolumn{2}{|c|}{$60(30-84)$} & $<0.0001$ \\
\hline Male, n (\%) & \multicolumn{2}{|c|}{$0(0.00 \%)$} & \multicolumn{2}{|c|}{$\begin{array}{l}39(52.0 \%) \\
\text { Breast cancer }(n=12), \text { II:10, III:2 } \\
\text { Colon cancer }(n=7), \text { II:3, III:4 } \\
\text { Gastric cancer }(n=9), \text { I:4, II:1, III:3, } \\
\text { IV:1 }\end{array}$} & $<0.0001$ \\
\hline $\begin{array}{c}\text { Tumour } \\
\text { type } \\
\text { and stage, n }\end{array}$ & \multicolumn{2}{|l|}{-} & $\begin{array}{r}\text { Breast cancer }( \\
\text { Colon cancer } \\
\text { Gastric cancer }( \\
\text { I } \\
\text { Melanoma ( } \\
\text { NSCLC }(n= \\
\text { Ovarian cance } \\
\text { I } \\
\text { Pancreatic car } \\
\text { ava } \\
\text { Prostate cancer } \\
\text { SCLC }(n=7),\end{array}$ & $\begin{array}{l}=12), \text { II: } 10, \text { III:2 } \\
=7), \text { II:3, III:4 } \\
=9), \text { I:4, II:1, III:3, } \\
1 \\
=6), \text { II:5, III: } 1 \\
\text {, I:5, II:3, III:3 } \\
(n=8), \text { I:1, III:2, } \\
5 \\
\text { er ( } n=2), \text { Not } \\
\text { able } \\
\text { = 13), I:1, II:12 } \\
\text { II:1, III:3, IV:1 }\end{array}$ & . \\
\hline Cohort 2 & $\begin{array}{l}\text { Healthy controls } \\
\qquad(n=35)\end{array}$ & $\operatorname{AD}(n=55)$ & $\operatorname{SCC}(n=39)$ & $\operatorname{COPD}(n=10)$ & $p$-Value \\
\hline $\begin{array}{c}\text { Age, } \\
\text { median } \\
(\min -\max )\end{array}$ & $60(51-72)$ & $62(41-78)$ & $62(50-71)$ & $54(50-60)$ & $<0.0001$ \\
\hline Male, n (\%) & $21(60 \%)$ & $21(42 \%)$ & $27(73 \%)$ & $5(50 \%)$ & 0.0339 \\
\hline $\begin{array}{l}\text { Tumour } \\
\text { stage, } \mathrm{n}\end{array}$ & - & $\begin{array}{c}\text { I:5, II:4, } \\
\text { III:22, IV:19 }\end{array}$ & $\begin{array}{c}\text { I:5, II:6, III:13, } \\
\text { IV:13 }\end{array}$ & - & - \\
\hline
\end{tabular}

Abbreviations: NSCLC, Non-small cell lung cancer; SCLC, small cell lung cancer; AD, adenocarcinoma; SCC, squamous cell carcinoma; COPD, chronic obstructive pulmonary fibrosis 

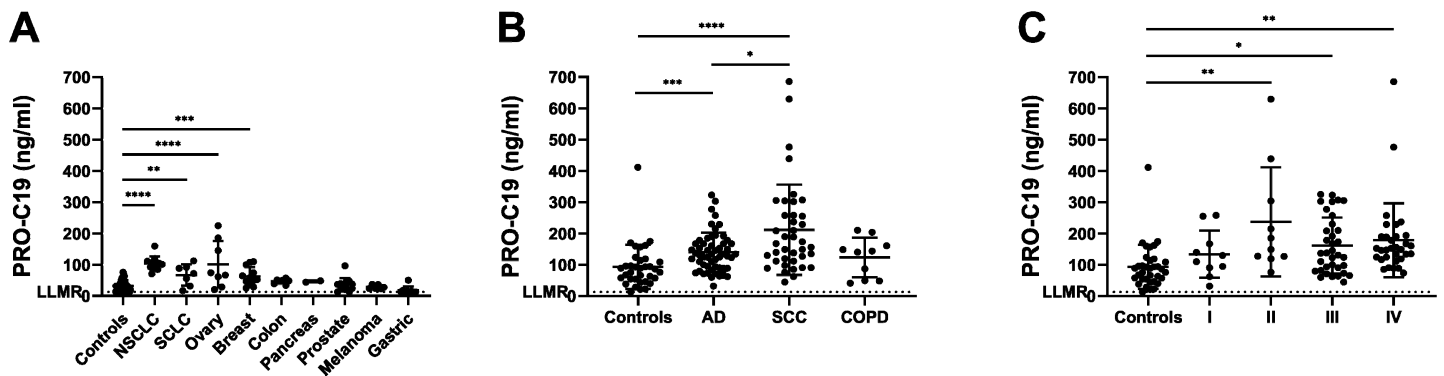

Figure 3. PRO-C19 in cohort 1 (A) and 2 (B and C). Quantification of PRO-C19 in the serum of: (A) healthy controls $(n=38)$ and a range of cancer types including NSCLC $(n=11)$, ovary $(n=8)$, SCLC $(n=7)$, breast $(n=12)$, colon $(n=7)$, pancreas $(n=2)$, prostate $(n=13)$, melanoma $(n=6)$, gastric $(n=9)$. (B) healthy controls $(n=35), \mathrm{AD}(n=55), \mathrm{SCC}(n=39)$ and COPD $(n=10)$. (C) healthy controls $(n=35)$, stage I $(n=10)$, stage II $(n=10)$, stage III $(n=35)$ and stage IV $(n=32)$. PRO-C19 levels are presented with mean and standard deviation. Samples measuring below the lower limit of measurement range (LLMR) were given the value of the LLMR, as determined in the validation of PRO-C19. Differences in PRO-C19 levels were evaluated by log-transforming the data and performing ordinary one-way ANOVA corrected for multiple comparisons with Tukey test. ${ }^{* * * *}$ indicates a $p$-value below 0.0001 . ${ }^{* * *}$ indicates a $p$-value below $0.001 .{ }^{* *}$ indicates a $p$-value below $0.01 .{ }^{*}$ indicates a $p$-value below 0.05 .

\subsection{PRO-C19 in Serum of NSCLC Patients (Cohort 2)}

Based on cohort 1 results, we decided to explore the role of PRO-C19 in NSCLC further. We therefore assessed PRO-C19 in an independent cohort of NSCLC patients including 55 AD patients and 39 SCC patients. The cohort also included 35 healthy controls and 10 chronic obstructive pulmonary disease (COPD) patients for comparison. For the AD group, 5 were stage I, 4 stage II, 22 stage III and 19 stage IV. For the SCC group, 5 were stage I, 6 stage II, 13 stage III and 13 stage IV (Table 2). Although there were slight variations in the age and gender proportions of the compared groups, we saw no association between PRO-C19 levels and age, gender, date of sample collection, BMI, smoking history, tumor grade, FEV1 or FEV1/FVC.

PRO-C19 levels were significantly elevated $(p=0.0003)$ with mean levels up to 1.5-fold higher for the AD group compared to controls (Figure 3B). A greater increase was seen in the SCC group, where mean PRO-C19 was significantly elevated $(p<0.0001)$ up to 2.25 -fold higher compared to controls. Interestingly, the SCC group measured significantly higher than AD $(p=0.0457)$ with a 1.5-fold higher mean PRO-C19 level. Contrastingly, although the COPD group measured slightly above the controls, this group was not significantly different than controls, AD or SCC. To evaluate PRO-C19 in relation to severity of disease we divided cohort 2 into TNM stages. PRO-C19 levels trended upwards in later stages (not significant) and was significantly elevated in stages II, III and IV compared to controls (Figure 3C). Overall, these results confirm that PRO-C19 levels are elevated in the circulation of NSCLC patients.

In terms of diagnostic accuracy, PRO-C19 could discriminate between AD and controls with an AUROC of 0.749 with a corresponding sensitivity of $69 \%$ and specificity of $74 \%$ at a cut-off of 108.5 $\mathrm{ng} / \mathrm{mL}$ (Table 3). Comparatively, discrimination between SCC and controls yielded an AUROC of 0.826 with a sensitivity of $72 \%$ and specificity of $83 \%$ at a cut-off of $124.1 \mathrm{ng} / \mathrm{mL}$. Interestingly, PRO-C19 could also discriminate between the AD and SCC groups with an AUROC of 0.654 with a sensitivity of $41 \%$ and specificity of $87 \%$ at a cut-off of $194 \mathrm{ng} / \mathrm{mL}$. Discrimination between COPD and the other groups was only significant for SCC with an AUROC of 0.690 with a sensitivity of $100 \%$ and specificity of 36\%. PRO-C19 could also discriminate between stages I+II and controls for both NSCLC subtypes: for AD stages I+II yielded an AUROC of 0.733 and for SCC an AUROC of 0.818 . 
Table 3. Summary of AUROC tests.

\begin{tabular}{|c|c|c|c|c|c|}
\hline Test & AUROC (95\%CI) & $p$-Value & Sensitivity, \% (95\%CI) & Specificity, \% (95\%CI) & $\begin{array}{l}\text { Cut-Off } \\
\text { (ng/mL) }\end{array}$ \\
\hline \multicolumn{6}{|l|}{ Cohort 1} \\
\hline Controls v NSCLC & $0.995(0.918-1.00)$ & $<0.0001$ & $100(71.5-100.0)$ & $94.74(82.3-99.4)$ & 63.3 \\
\hline Controls v SCLC & $0.808(0.663-0.910)$ & 0.0048 & $71.4(29.0-96.3)$ & $84.2(68.7-94.0)$ & 54.3 \\
\hline Controls v breast cancer & $0.814(0.678-0.910)$ & $<0.0001$ & $75.0(42.8-94.5)$ & $78.95(62.7-90.4)$ & 41.9 \\
\hline Controls v ovarian cancer & $0.839(0.701-0.931)$ & 0.0003 & $75.0(34.9-96.8)$ & $92.1(78.6-98.3)$ & 60.3 \\
\hline \multicolumn{6}{|l|}{ Cohort 2} \\
\hline Controls v AD+SCC & $0.781(0.700-0.849)$ & $<0.0001$ & $73.4(63.3-82.0)$ & $74.29(56.7-87.5)$ & 108.5 \\
\hline Controls v AD & $0.749(0.647-0.835)$ & $<0.0001$ & $69.09(55.2-80.9)$ & $74.29(56.7-87.5)$ & 108.5 \\
\hline Controls v SCC & $0.826(0.721-0.905)$ & $<0.0001$ & $71.79(55.1-85.0)$ & $82.86(66.4-93.4)$ & 124.1 \\
\hline AD vs SCC & $0.654(0.548-0.749)$ & 0.0096 & $41.03(25.6-57.9)$ & $87.27(75.5$ - 94.7) & 194.0 \\
\hline Controls v COPD & $0.646(0.489-0.782)$ & 0.1926 & $60.00(26.2-87.8)$ & $82.86(66.4-93.4)$ & 124.1 \\
\hline AD vs COPD & $0.556(0.428-0.680)$ & 0.6251 & $30.00(6.7-65.2)$ & $98.18(90.3-100.0)$ & 49.1 \\
\hline SCC vs COPD & $0.690(0.542-0.814)$ & 0.0377 & $100.00(69.2-100.0)$ & $35.90(21.2-52.8)$ & 210.2 \\
\hline Controls v AD I+II & $0.733(0.579-0.855)$ & 0.0197 & $88.89(51.8-99.7)$ & $57.14(39.4-73.7)$ & 89.1 \\
\hline Controls v AD III+IV & $0.756(0.644-0.847)$ & $<0.0001$ & $68.29(51.9-81.9)$ & $77.14(59.9-89.6)$ & 113.9 \\
\hline Controls v SCC I+II & $0.818(0.677-0.916)$ & $<0.0001$ & $81.82(48.2-97.7)$ & $80.00(63.1-91.6)$ & 118.9 \\
\hline Controls v SCC III+IV & $0.833(0.716-0.916)$ & $<0.0001$ & $73.08(52.2-88.4)$ & $82.86(66.4-93.4)$ & 124.1 \\
\hline
\end{tabular}

Abbreviations: AUROC, area under receiver operating characteristics

\subsection{COL19A1 Gene Expression in Publicly Available Lung Cancer Databases}

To support the relevance of type XIX collagen in lung cancer, we investigated the COL19A1 gene expression levels in normal lung and lung cancer using publicly available data from The Cancer Genome Atlas (TCGA) [26] and Genotype-Tissue Expression (GTEx) initiatives [27]. The normal lung dataset included 347 samples for AD and 338 for SCC, each comprising normal samples from the GTEx dataset and tumor-adjacent normal lung tissue from the TCGA AD and SCC datasets. The NSCLC dataset included 513 AD samples and 498 SCC samples. Median COL19A1 expression was significantly elevated in $\mathrm{AD}(p<0.0001)$ and SCC $(p<0.0001)$ patients compared to their respective normal groups (Figure 4). SCC was also significantly elevated compared to AD $(p<0.0001)$. These data are in agreement with our assessment of PRO-C19 levels in circulation.

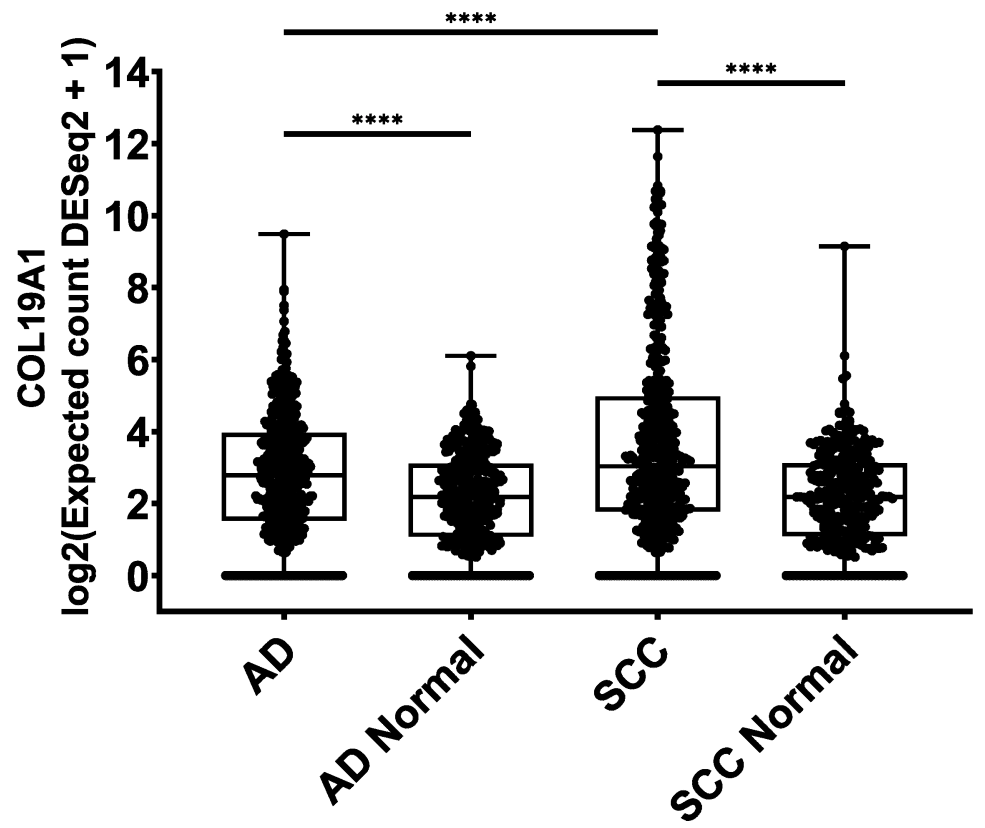

Figure 4. COL19A1 gene expression from the The Cancer Genome Atlas (TCGA) and Genotype-Tissue Expression (GTEx) databases in AD $(n=513)$, AD normal $(n=347)$, SCC $(n=498)$ and SCC normal $(n=338)$. The AD and SCC normal groups included normal samples from GTEx and tumor-adjacent normal samples from AD and SCC patients, respectively. 


\section{Discussion}

The current study demonstrates the technical validation of an ELISA measuring the C-terminus of type XIX collagen named PRO-C19. PRO-C19 was specific towards the intended epitope and was technically robust. PRO-C19 was assessed in a panel of serum samples from healthy individuals, cancer patients and COPD patients to demonstrate biological relevance and biomarker potential. PRO-C19 levels were elevated in several types of cancer and could discriminate between NSCLC and healthy individuals with significant diagnostic accuracy in early stages of NSCLC.

To our knowledge, a description of type XIX collagen in the human lung is lacking and the presence of type XIX collagen in connection to lung cancer has not been demonstrated. Hence, this is the first study to demonstrate an association between lung cancer and type XIX collagen. Type XIX collagen has been observed in moderate amounts in the lungs of mice embryos, whereas only trace amounts were seen in adults, which could suggest a developmental role of type XIX collagen in the lungs [28]. Such an expression pattern is seen in several proteins and pathways important for cancer progression, and indeed several aspects of the developmental process are reactivated during tumorigenesis, including epithelial-mesenchymal transition [29-31]. Thus, a role in development could hint at a role in cancer as well.

PRO-C19 was excellent at discriminating between controls and some of the different cancer types, in particular NSCLC. As accuracy was also good in earlier stages of disease this could suggest that elevated levels of PRO-C19 may arise early in disease progression, potentially only in a subset of patients. Furthermore, future studies into early detection could also assess PRO-C19 in high-risk individuals before an eventual NSCLC diagnosis. Based on our limited data from COPD patients, we saw no elevated PRO-C19 levels, suggesting that PRO-C19 is not associated with lung disorders in general, but could instead be a more cancer-specific characteristic. A follow-up study further assessing PRO-C19 in COPD and other lung disorders such as idiopathic pulmonary fibrosis would be needed to confirm this. Our research group has developed several other ECM protein markers that have shown biological relevance in lung cancer [11,32-38]. Future studies should investigate combining PRO-C19 with these markers and other NSCLC biomarkers to improve overall accuracy.

In human adults, type XIX collagen expression can be very limited as exemplified by the $10^{-6 \%}$ of the dry weight of umbilical cord tissue that type XIX collagen amounted to [39]. However, a separate study quantifying type XIX collagen in different tissue extracts and biological fluids found it detectable in the circulation [40]. Based on our data, type XIX collagen is released into circulation of healthy adults in modest amounts and circulating type XIX collagen levels are significantly increased in some cancer types. Type XIX collagen has previously been linked to breast cancer progression where, as the BMZ surrounding breast tumors was broken down during cancer progression, the staining of type XIX collagen protein was lost [22]. Based on our very limited data, an increase in the levels of circulating type XIX collagen is also linked to breast cancer. Type XIX collagen expression is strongly associated with the BMZ in general and the breakdown of the epithelial and vascular BMZ of the breast could lead to the release of type XIX collagen into circulation. It is important to note that there can be distinct differences in the organization of the BMZ of different tumor types e.g., the epithelial BMZ is broken down around invasive carcinomas of the breast, whereas it can remain intact around invasive glands in epithelial malignancies [22,41].

Anti-tumor properties have been assigned to type XIX collagen. The NC1 domain can, once cleaved off, inhibit invasion and angiogenesis in melanoma [25]. This was demonstrated in an in vivo mouse model where the NC1 (XIX) peptide inhibited tumor growth, and where the NC1 (XIX) peptide inhibited angiogenesis by matrix metalloproteinase- 14 and vascular endothelial growth factor inhibition [23]. It was later discovered that NC1 (XIX) signaling is likely mediated by the $\alpha \mathrm{v} \beta 3$ integrin [25]. In a separate study, it was demonstrated that the NC1 (XIX) peptide could promote the formation of inhibitory nerve terminals through $\alpha 5 \beta 1$ integrin [42]. These integrin receptors are expressed by both epithelial and endothelial lung cells and can play a role in NSCLC, so it would be interesting to see the effects of NC1 (XIX) peptides in lung cancer [43-45]. Based on the peptides 
described in the literature, PRO-C19 is not specific towards the neo-epitope generated during plasmin cleavage of the NC1 domain. However, it can quantify any fragment containing the C-terminal epitope. Knowledge of how type XIX collagen is cleaved or otherwise processed is lacking, so PRO-C19 could hypothetically measure a large and diverse population of type XIX collagen fragments that all contain the C-terminal epitope. Further investigation into how type XIX collagen is processed and if any specific fragments can be quantified in circulation is warranted. Type XIX collagen has also been linked to neurodegenerative diseases including amyotrophic lateral sclerosis and Parkinson's. Type XIX collagen expression is downregulated in the peripheral blood of Parkinson's patients [46]. Contrastingly, in amyotrophic lateral sclerosis, type XIX collagen increased with progressing disease and increased mortality risk [47-49]. This is another avenue where the PRO-C19 assay could prove useful.

This study has several major limitations: Given the strictly exploratory nature of this study, the use of so-called "samples of convenience" and post-hoc analysis can introduce bias. In numbers, this bias is evidenced by the differences in sample sizes, age and gender of the compared groups. However, we did not observe any connection with PRO-C19 levels and these parameters in our limited dataset. Clinical data of the study participants was also limited, so additional hidden bias could also arise. Importantly, a study with substantially larger sample sizes is necessary to explore where PRO-C19 could prove useful in the clinical setting. The results of this study are therefore merely our first attempt at probing the biology of type XIX collagen in cancer. A limitation of our approach to type XIX collagen quantification is that the source tissue cannot be determined, although the tissue the tumor is found in is the likely contributor. Overall though, how the breakdown of the BMZ and circulating type XIX collagen are connected warrants further investigation. To support our findings using the PRO-C19 assay, we used COL19A1 gene expression data from the TCGA and GTEx initiatives to confirm the elevated levels of type XIX collagen in NSCLC. We saw elevated levels for AD and SCC compared to their respective control groups and COL19A1 levels in SCC were significantly higher than in AD. This is in accordance with the PRO-C19 data described above.

\section{Materials and Methods}

\subsection{PRO-C19 ELISA Protocol}

The ten amino acid peptide ${ }^{1133}$ SHAHQRTGGN ${ }^{1142}$ found in the very C-terminus of type XIX collagen (UniProtKB: Q14993) was purchased from Genscript (Piscataway, NJ, USA) and used for immunization. The production of monoclonal antibodies has been described elsewhere [32]. Several optimizations were made to the ELISA including the choice of assay buffer, incubation time and temperature as well as concentrations of antibody and peptides. The final PRO-C19 protocol was performed as follows: a 96-well streptavidin-coated ELISA plate was coated with $100 \mu \mathrm{l} /$ well of $2.5 \mathrm{ng} / \mathrm{mL}$ biotinylated SHAHQRTGGN peptide dissolved in assay buffer (25 mM Tris-buffered saline, $1 \%$ bovine serum albumin (w/v), 0.1\% Tween-20 (w/v), $2 \mathrm{~g} / 1 \mathrm{NaCl}, \mathrm{pH} 8.0)$ and incubated for $30 \mathrm{~min}$ at $20{ }^{\circ} \mathrm{C}$ with shaking at 300 revolutions-per-minute (RPM). After washing five times with washing buffer (25 mM Tris, $50 \mathrm{mM} \mathrm{NaCl}, \mathrm{pH}$ 7.2), $20 \mu \mathrm{l} /$ well of sample was added in duplicates followed by $100 \mu \mathrm{l} /$ well of $60 \mathrm{ng} / \mathrm{mL}$ Horseradish peroxidase-labelled monoclonal antibody in assay buffer and incubated for $1 \mathrm{~h}$ at $20^{\circ} \mathrm{C}$ with shaking at $300 \mathrm{RPM}$. After a second washing cycle, $100 \mu \mathrm{l} /$ well of 3,3',5,5'-tetramethylbenzidine was added and incubated $15 \mathrm{~min}$ in darkness at $20{ }^{\circ} \mathrm{C}$ with shaking at $300 \mathrm{RPM}$. The reaction was stopped by adding $100 \mu \mathrm{l} /$ well of $1 \% \mathrm{H}_{2} \mathrm{SO}_{4}$. Absorbance was measured at $450 \mathrm{~nm}$ with $650 \mathrm{~nm}$ as reference. To generate a standard curve, $20 \mu \mathrm{l} /$ well of $500 \mathrm{ng} / \mathrm{mL}$ SHAHQRTGGN peptide, serially diluted twofold, was added to appropriate wells and a four-parametric mathematical fit was used to generate the curve. Each plate included 5 quality control samples comprising one human serum, one horse serum, one bovine cartilage explant and two peptide-in-assay-buffer samples to monitor intra- and inter-assay variation. 


\subsection{Technical Validation of the PRO-C19 ELISA}

Antibody specificity was tested by the inhibition of signal by twofold dilutions of the standard peptide (SHAHQRTGGN), elongated peptide (SHAHQRTGGNA), truncated peptide (SHAHQRTGG) as well as non-sense standard peptide (GVAPGIGPGG) and a non-sense coater peptide (Biotin-GVAPGIGPGG). Linearity or parallelism was tested by serially diluting human serum samples twofold and calculating the percentage recovery relative to the dilution. Accuracy was tested by spiking the standard peptide into a human serum sample and calculating the percentage recovery of the peptide in the spiked sample. The influence of commonly interfering substances including hemoglobin, lipids and biotin were evaluated by spiking human serum samples up to either a high or low concentration of the interfering agents (hemoglobin low $=2.5 \mathrm{mg} / \mathrm{mL}$, high $=5 \mathrm{mg} / \mathrm{mL}$; lipid low $=1.5 \mathrm{mg} / \mathrm{mL}$, high $=5 \mathrm{mg} / \mathrm{mL}$; biotin low $=3 \mathrm{ng} / \mathrm{mL}$, high $=9 \mathrm{ng} / \mathrm{mL}$ ). Impact of spiking with the interference agents was calculated as the percentage recovery of the spiked sample relative to the non-spiked sample. Assay variation was tested by ten independent runs using ten quality control samples run in double-determinations. Five of the quality control samples were human serum, one was horse serum, one was bovine cartilage explant and three were standard peptide in assay buffer of varying concentrations. Intra-assay variation was calculated as the mean coefficient of variance for the double determinations of each of the ten runs. Inter-assay variation was calculated as the overall coefficient of variance across the ten runs. Lower- and upper-limits of measurement range (LLMR and ULMR, respectively) were determined across the ten independent runs and denote the boundaries of the linear range of the standard curve. Analyte stability was determined for three human serum samples incubated at 4 or $20^{\circ} \mathrm{C}$ for $2,4,24$ or $48 \mathrm{~h}$. Stability was calculated as the percentage recovery of the incubated sample relative to the control sample kept at $-20{ }^{\circ} \mathrm{C}$. Freeze-thaw stability was evaluated by freezing and thawing human serum samples up to 4 cycles. Stability was calculated as the percentage recovery of the thawed sample relative to the sample that underwent a single freeze-thaw cycle. Lower limit of detection was calculated as the mean concentration of 21 blank samples containing assay buffer with 3 standard deviations added. Upper limit of detection was calculated as the mean concentration of standard peptide corresponding to the highest concentration of the standard curve across the ten independent runs with 3 standard deviations subtracted.

\subsection{Patient Samples}

The first cohort was in part obtained from the commercial vendor Asterand (Detroit, MI, USA). It included serum from 75 cancer patients including breast cancer $(n=12)$, colon cancer $(n=7)$, gastric cancer $(n=9)$, melanoma $(n=6), \operatorname{NSCLC~}(n=11)$, ovarian cancer $(n=8)$, pancreatic cancer $(n=2)$, prostate cancer $(n=13), \operatorname{SCLC}(n=7)$ along with 38 healthy controls in part from Asterand and in part from another study population (reg. no. KA99070gm) [50]. The second cohort was obtained from the commercial vendor Proteogenex (Los Angeles, CA, USA). It included 55 AD patients of which 5 were stage I, 4 stage II, 22 stage III and 19 stage IV. It also included 39 SCC patients of which 5 were stage I, 6 stage II, 13 stage III and 13 stage IV. It also included 10 COPD patients and lastly 35 healthy controls obtained from Proteogenex and BioIVT (Westbury, NY, USA). According to the vendors, sample collection was approved by an Institutional Review Board or Independent Ethical Committee and patients gave their informed consent (Protocol numbers PG-ONC 2003/1 and WIRBßProtocol \#20161665). All investigations were carried out according to the Helsinki Declaration.

\subsection{Analysis of Publicly Available Genomics Databases}

The UCSC Xena browser (http://xena.ucsc.edu/) was used to access the TCGA (https://www.cancer. gov/tcga) and GTEx (https://www.gtexportal.org/) datasets. In the Xena browser we used the TCGA TARGET GTEx combined cohort and filtered down to TCGA and GTEx lung samples. We used RSEM expected count (DESeq2 standardized) UCSC Toil RNA-seq Recomputed data for COL19A1 gene expression. How this data has been processed and standardized has been described elsewhere [51-54]. 
We pooled together the GTEx normal lung data with either TCGA normal AD or SCC data to make two groups for comparison with the TCGA AD or SCC primary tumor data.

\subsection{Statistics:}

PRO-C19 levels were log (10) transformed and tested for normality by D'Agostino-Pearson omnibus test. Comparison of PRO-C19 levels across groups was done using ordinary one-way ANOVA corrected for multiple comparisons using Tukey test. Differences in age between groups was evaluated using Mann-Whitney test if comparing two groups and Kruskal-Wallis test if comparing more. Differences in gender was evaluated using Fisher's exact test if comparing two groups and Chi-square test if comparing more. The correlation between PRO-C19 levels and BMI, age, smoking etc. was evaluated using linear regression. Diagnostic accuracy was tested by the AUROC curve. Sensitivity and specificity were determined at the estimated optimal cut-off value according to the Youden Index. A $p$ value below 0.05 was considered significant. Asterisks indicate the following significance levels: ${ }^{*} p<0.05 ;{ }^{* *} p<0.01 ;{ }^{* *} p<0.001 ;{ }^{* * *} p<0.0001$. When doing multiple comparisons tests, multiplicity adjusted $p$-values are reported. Statistical analysis and graphs were done in GraphPad Prism (version 8.2 for Windows, GraphPad Software, San Diego, CA, USA, www.graphpad.com) and MedCalc (MedCalc Statistical Software version 18.11.6 (MedCalc Software bvba, Ostend, Belgium; https://www.medcalc.org; 2019).

\section{Conclusions}

In conclusion, we developed and validated an ELISA targeting the C-terminus of type XIX collagen, named PRO-C19. PRO-C19 was used to quantify type XIX collagen in the serum of cancer patients, where it was significantly elevated in several cancer types as compared to healthy controls. PRO-C19 was subsequently assessed in a separate NSCLC cohort where it was also significantly elevated and exhibited diagnostic accuracy in early stage NSCLC. Elevated levels of type XIX collagen in NSCLC patients were confirmed using publicly available gene expression data. In all, type XIX collagen shows potential as a cancer biomarker and further studies into its use are warranted.

\section{Patents}

A patent for the PRO-C19 assay is on file and is owned by Nordic Bioscience.

Author Contributions: Conceptualization, J.T.-U., M.K. and N.W.; methodology, J.T.-U. and N.W.; formal analysis, J.T.-U.; investigation, J.T.-U.; resources, N.W., T.M.-J., S.S., D.J.L. and J.M.S.; writing-original draft preparation, J.T.-U.; writing-review and editing, J.T.-U., M.K. and N.W.; visualization, J.T.-U.; supervision, M.K. and N.W.; project administration, N.W.; funding acquisition, M.K. All authors have read and agreed to the published version of the manuscript.

Funding: This research was funded by the Danish Research Foundation.

Conflicts of Interest: All authors are employed at Nordic Bioscience involved in biomarker discovery and assay development. The funders had no role in the design of the study; in the collection, analyses, or interpretation of data; in the writing of the manuscript, or in the decision to publish the results.

\section{References}

1. Bray, F.; Ferlay, J.; Soerjomataram, I.; Siegel, R.L.; Torre, L.A.; Jemal, A. Global cancer statistics 2018: GLOBOCAN estimates of incidence and mortality worldwide for 36 cancers in 185 countries. CA A Cancer J. Clin. 2018, 68, 394-424. [CrossRef]

2. Molina, J.R.; Yang, P.; Cassivi, S.D.; Schild, S.E.; Adjei, A.A. Non-Small Cell Lung Cancer: Epidemiology, Risk Factors, Treatment, and Survivorship. Mayo Clin. Proc. 2008, 83, 584-594. [CrossRef]

3. Herbst, R.S.; Morgensztern, D.; Boshoff, C. The biology and management of non-small cell lung cancer. Nature 2018, 553, 446-454. [CrossRef]

4. Siegel, R.L.; Miller, K.D.; Jemal, A. Cancer statistics, 2019. CA A Cancer J. Clin. 2019, 69, 7-34. [CrossRef] [PubMed] 
5. Hanahan, D.A.; Weinberg, R. Hallmarks of Cancer: The Next Generation. Cell 2011, 144, 646-674. [CrossRef]

6. Pickup, M.W.; Mouw, J.K.; Weaver, V.M. The extracellular matrix modulates the hallmarks of cancer. EMBO Rep. 2014, 15, 1243-1253. [CrossRef]

7. Ricard-Blum, S. The collagen family. Cold Spring Harb. Perspect. Biol. 2011, 3, a004978. [CrossRef]

8. Willumsen, N.; Bager, C.L.; Leeming, D.J.; Smith, V.; Karsdal, M.A.; Dornan, D.; Bay-Jensen, A.-C. Extracellular matrix specific protein fingerprints measured in serum can separate pancreatic cancer patients from healthy controls. BMC Cancer 2013, 13, 554. [CrossRef]

9. Willumsen, N.; Bager, C.L.; Leeming, D.J.; Smith, V.; Christiansen, C.; Karsdal, M.A.; Dornan, D.; Bay-Jensen, A.-C. Serum biomarkers reflecting specific tumor tissue remodeling processes are valuable diagnostic tools for lung cancer. Cancer Med. 2014, 3, 1136-1145. [CrossRef] [PubMed]

10. Lipton, A.; Leitzel, K.; Ali, S.M.; Polimera, H.V.; Nagabhairu, V.; Marks, E.; Richardson, A.E.; Krecko, L.; Ali, A.; Koestler, W.; et al. High turnover of extracellular matrix reflected by specific protein fragments measured in serum is associated with poor outcomes in two metastatic breast cancer cohorts. Int. J. Cancer 2018, 143, 3027-3034. [CrossRef] [PubMed]

11. Thorlacius-Ussing, J.; Kehlet, S.N.; Rønnow, S.R.; Karsdal, M.A.; Willumsen, N. Non-invasive profiling of protease-specific elastin turnover in lung cancer: Biomarker potential. J. Cancer Res. Clin. Oncol. 2018, 145, 383-392. [CrossRef]

12. Jensen, C.; Madsen, D.H.; Hansen, M.; Schmidt, H.; Svane, I.M.; Karsdal, M.A.; Willumsen, N. Non-invasive biomarkers derived from the extracellular matrix associate with response to immune checkpoint blockade (anti-CTLA-4) in metastatic melanoma patients. J. Immunother. Cancer 2018, 6, 152. [CrossRef]

13. Willumsen, N.; Jørgensen, L.N.; Karsdal, M.A. Vastatin (the NC1 domain of human type VIII collagen a1 chain) is linked to stromal reactivity and elevated in serum from patients with colorectal cancer. Cancer Boil. Ther. 2019, 20, 692-699. [CrossRef]

14. Willumsen, N.; Bager, C.A.; Karsdal, M. Matrix Metalloprotease Generated Fragments of Type VI Collagen Have Serum Biomarker Potential in Cancer - A Proof of Concept Study. Transl. Oncol. 2019, 12, 693-698. [CrossRef]

15. Banys-Paluchowski, M.; Loibl, S.; Witzel, I.; Mundhenke, C.; Lederer, B.; Solbach, C.; Karn, T.; Marmé, F.; Nekljudova, V.; Schem, C.; et al. Clinical Relevance of Collagen Protein Degradation Markers C3M and C4M in the Serum of Breast Cancer Patients Treated with Neoadjuvant Therapy in the GeparQuinto Trial. Cancers 2019, 11, 1186. [CrossRef]

16. Chen, I.M.; Willumsen, N.; Dehlendorff, C.; Johansen, A.Z.; Jensen, B.V.; Hansen, C.P.; Hasselby, J.P.; Bojesen, S.E.; Pfeiffer, P.; Nielsen, S.E.; et al. Clinical value of serum hyaluronan and propeptide of type III collagen in patients with pancreatic cancer. Int. J. Cancer 2019, 146, 2913-2922. [CrossRef] [PubMed]

17. Willumsen, N.; Ali, S.M.; Leitzel, K.; Drabick, J.J.; Yee, N.; Polimera, H.V.; Nagabhairu, V.; Krecko, L.; Ali, A.; Maddukuri, A.; et al. Collagen fragments quantified in serum as measures of desmoplasia associate with survival outcome in patients with advanced pancreatic cancer. Sci. Rep. 2019, 9, 1-8. [CrossRef] [PubMed]

18. Yoshioka, H.; Zhang, H.; Ramirez, F.; Mattei, M.-G.; Moradi-Améli, M.; Van Der Rest, M.; Gordon, M.K. Synteny between the loci for a novel FACIT-like collagen locus (D6S228E) and $\alpha 1$ (IX) collagen (COL9A1) on 6q12-q14 in humans. Genomics 1992, 13, 884-886. [CrossRef]

19. Inoguchi, K.; Yoshioka, H.; Khaleduzzaman, M.; Ninomiya, Y. The mRNA for $\alpha 1($ XIX) Collagen Chain, a New Member of FACITs, Contains a Long Unusual 3' Untranslated Region and Displays Many Unique Splicing Variants1. J. Biochem. 1995, 117, 137-146. [CrossRef]

20. Myers, J.C.; Yang, H.A.; D'Ippolito, J.; Presente, A.; Miller, M.K.; Dion, A.S. The triple-helical region of human type XIX collagen consists of multiple collagenous subdomains and exhibits limited sequence homology to alpha 1(XVI). J. Boil. Chem. 1994, 269, 18549-18557.

21. Myers, J.C.; Li, D.; Bageris, A.; Abraham, V.; Dion, A.S.; Amenta, P.S. Biochemical and immunohistochemical characterization of human type XIX defines a novel class of basement membrane zone collagens. Am. J. Pathol. 1997, 151, 1729-1740.

22. Amenta, P.S.; Hadad, S.; Lee, M.T.; Barnard, N.; Li, D.; Myers, J.C. Loss of types XV and XIX collagen precedes basement membrane invasion in ductal carcinoma of the female breast. J. Pathol. 2003, 199, 298-308. [CrossRef] 
23. Ramont, L.; Brassart-Pasco, S.; Thevenard, J.; Deshorgue, A.; Venteo, L.; Laronze, J.Y.; Pluot, M.; Monboisse, J.C.; Maquart, F.-X. The NC1 domain of type XIX collagen inhibits in vivo melanoma growth. Mol. Cancer Ther. 2007, 6, 506-514. [CrossRef]

24. Oudart, J.-B.; Brassart-Pasco, S.; Vautrin, A.; Sellier, C.; Machado, C.; Dupont-Deshorgue, A.; Brassart, B.; Baud, S.; Dauchez, M.; Monboisse, J.-C.; et al. Plasmin releases the anti-tumor peptide from the NC1 domain of collagen XIX. Oncotarget 2015, 6, 3656-3668. [CrossRef]

25. Oudart, J.-B.; Doué, M.; Vautrin, A.; Brassart, B.; Sellier, C.; Dupont-Deshorgue, A.; Monboisse, J.-C.; Maquart, F.-X.; Brassart-Pasco, S.; Ramont, L. The anti-tumor NC1 domain of collagen XIX inhibits the FAK/ PI3K/Akt/mTOR signaling pathway through $\alpha \mathrm{v} \beta 3$ integrin interaction. Oncotarget 2015, 7, 1516-1528. [CrossRef]

26. The Cancer Genome Atlas Program. Available online: https://www.cancer.gov/tcga (accessed on 29 May 2020).

27. The Genotype-Tissue Expression (GTEx) Project. Available online: https://www.gtexportal.org (accessed on 29 May 2020).

28. Sumiyoshi, H.; Inoguchi, K.; Khaleduzzaman, M.; Ninomiya, Y.; Yoshioka, H. Ubiquitous Expression of the $\alpha 1$ (XIX) Collagen Gene (Col19a1) during Mouse Embryogenesis Becomes Restricted to a Few Tissues in the Adult Organism. J. Boil. Chem. 1997, 272, 17104-17111. [CrossRef]

29. Sedgwick, A.E.; D'Souza-Schorey, C. Wnt Signaling in Cell Motility and Invasion: Drawing Parallels between Development and Cancer. Cancers 2016, 8, 80. [CrossRef]

30. Giroux-Leprieur, E.; Costantini, A.; Ding, V.W.; He, B. Hedgehog Signaling in Lung Cancer: From Oncogenesis to Cancer Treatment Resistance. Int. J. Mol. Sci. 2018, 19, 2835. [CrossRef]

31. Chaffer, C.L.; Juan, B.P.S.; Lim, E.A.; Weinberg, R. EMT, cell plasticity and metastasis. Cancer Metastasis Rev. 2016, 35, 645-654. [CrossRef]

32. Kehlet, S.; Manon-Jensen, T.; Sun, S.; Brix, S.; Leeming, D.; Karsdal, M.A.; Willumsen, N. A fragment of SPARC reflecting increased collagen affinity shows pathological relevance in lung cancer - implications of a new collagen chaperone function of SPARC. Cancer Boil. Ther. 2018, 19, 1-9. [CrossRef]

33. Nissen, N.I.; Karsdal, M.; Willumsen, N. Post-translational modifications of vimentin reflect different pathological processes associated with non-small cell lung cancer and chronic obstructive pulmonary disease. Oncotarget 2019, 10, 6829-6841. [CrossRef]

34. Leeming, D.J.; Willumsen, N.; Sand, J.; Nielsen, S.H.; Dasgupta, B.; Brodmerkel, C.; Curran, M.; Bager, C.; Karsdal, M.A. A serological marker of the N-terminal neoepitope generated during LOXL2 maturation is elevated in patients with cancer or idiopathic pulmonary fibrosis. Biochem. Biophys. Rep. 2018, 17, 38-43. [CrossRef] [PubMed]

35. Nielsen, S.H.; Willumsen, N.; Leeming, D.J.; Daniels, S.J.; Brix, S.; Karsdal, M.A.; Genovese, F.; Nielsen, M.J. Serological Assessment of Activated Fibroblasts by alpha-Smooth Muscle Actin ( $\alpha$-SMA): A Noninvasive Biomarker of Activated Fibroblasts in Lung Disorders. Transl. Oncol. 2018, 12, 368-374. [CrossRef]

36. Nielsen, S.H.; Willumsen, N.; Brix, S.; Sun, S.; Manon-Jensen, T.; Karsdal, M.; Genovese, F. Tumstatin, a Matrikine Derived from Collagen Type IV $\alpha 3$, is Elevated in Serum from Patients with Non-Small Cell Lung Cancer. Transl. Oncol. 2018, 11, 528-534. [CrossRef]

37. Kehlet, S.; Bager, C.; Willumsen, N.; Dasgupta, B.; Brodmerkel, C.; Curran, M.; Brix, S.; Leeming, D.J.; Karsdal, M.A. Cathepsin-S degraded decorin are elevated in fibrotic lung disorders - development and biological validation of a new serum biomarker. BMC Pulm. Med. 2017, 17, 110. [CrossRef]

38. Willumsen, N.; Bager, C.L.; Leeming, D.J.; Bay-Jensen, A.-C.; Karsdal, M.A. Nidogen-1 Degraded by Cathepsin S can be Quantified in Serum and is Associated with Non-Small Cell Lung Cancer. Neoplasia 2017, 19, 271-278. [CrossRef]

39. Myers, J.C.; Li, D.; Amenta, P.S.; Clark, C.C.; Nagaswami, C.; Weisel, J.W. Type XIX Collagen Purified from Human Umbilical Cord Is Characterized by Multiple Sharp Kinks Delineating Collagenous Subdomains and by Intermolecular Aggregates via Globular, Disulfide-linked, and Heparin-binding Amino Termini. J. Boil. Chem. 2003, 278, 32047-32057. [CrossRef]

40. Oudart, J.; Brassart-Pasco, S.; Luczka, E.; Dupont-Deshorgue, A.; Bellon, G.; Boudko, S.; Bachinger, H.; Monboisse, J.C.; Maquart, F.-X.; Ramont, L. Analytical methods for measuring collagen XIX in human cell cultures, tissue extracts, and biological fluids. Anal. Biochem. 2013, 437, 111-117. [CrossRef]

41. Määttä, M.; Virtanen, I.; Burgeson, R.; Autio-Harmainen, H. Comparative Analysis of the Distribution of Laminin Chains in the Basement Membranes in Some Malignant Epithelial Tumors: The ?1 Chain 
of Laminin Shows a Selected Expression Pattern in Human Carcinomas. J. Histochem. Cytochem. 2001, 49, 711-725. [CrossRef]

42. Su, J.; Chen, J.; Lippold, K.; Monavarfeshani, A.; Carrillo, G.L.; Jenkins, R.A.; Fox, M. Collagen-derived matricryptins promote inhibitory nerve terminal formation in the developing neocortex. J. Cell Boil. 2016, 212, 721-736. [CrossRef]

43. Caccavari, F.; Valdembri, D.; Sandri, C.; Bussolino, F.; Serini, G.G. Integrin signaling and lung cancer. Cell Adhes. Migr. 2010, 4, 124-129. [CrossRef]

44. Singh, B.; Fu, C.; Bhattacharya, J. Vascular expression of the $\alpha \mathrm{v} \beta 3$-integrin in lung and other organs. Am. J. Physiol. Cell. Mol. Physiol. 2000, 278, L217-L226. [CrossRef]

45. Schaffner, F.; Ray, A.-M.; Dontenwill, M. Integrin $\alpha 5 \beta 1$, the Fibronectin Receptor, as a Pertinent Therapeutic Target in Solid Tumors. Cancers 2013, 5, 27-47. [CrossRef] [PubMed]

46. Infante, J.; Prieto, C.; Sierra, M.; Sánchez-Juan, P.; González-Aramburu, I.; Sánchez-Quintana, C.; Berciano, J.; Combarros, O.; Sainz, J. Identification of candidate genes for Parkinson's disease through blood transcriptome analysis in LRRK2-G2019S carriers, idiopathic cases, and controls. Neurobiol. Aging 2015, 36, 1105-1109. [CrossRef] [PubMed]

47. Shtilbans, A.; Choi, S.G.; Fowkes, M.E.; Khitrov, G.; Shahbazi, M.; Ting, J.; Zhang, W.; Sun, Y.; Sealfon, S.C.; Lange, D.J. Differential gene expression in patients with amyotrophic lateral sclerosis. Amyotroph. Lateral Scler. 2011, 12, 250-256. [CrossRef]

48. Calvo, A.; Manzano, R.; Atencia-Cibreiro, G.; Oliván, S.; Muñoz, M.J.; Zaragoza, P.; Cordero-Vázquez, P.; Esteban-Pérez, J.; García-Redondo, A.; Osta, R. Genetic Biomarkers for ALS Disease in Transgenic SOD1G93A Mice. PLoS ONE 2012, 7, e32632. [CrossRef]

49. Calvo, A.; Cibreiro, G.A.; Merino, P.T.; Roy, J.F.; Galiana, A.; Rufián, A.J.; Cano, J.M.; Martínez, L.M.; Moreno, L.; Larrodé, P.; et al. Collagen XIX Alpha 1 Improves Prognosis in Amyotrophic Lateral Sclerosis. Aging Dis. 2019, 10, 278-292. [CrossRef]

50. Neergaard, J.; Dragsbæk, K.; Kehlet, S.; Hansen, H.; Hansen, G.; Byrjalsen, I.; Alexandersen, P.; Lindgren, L.; Bihlet, A.; Riis, B.; et al. Cohort Profile: The Prospective Epidemiological Risk Factor (PERF) study. Int. J. Epidemiol. 2016, 46, 1104. [CrossRef]

51. Goldman, M.; Craft, B.; Hastie, M.; Repečka, K.; Kamath, A.; McDade, F.; Rogers, D.; Brooks, A.N.; Zhu, J.; Haussler, D.; et al. The UCSC Xena platform for public and private cancer genomics data visualization and interpretation 2018, 326470. BioRxiv 2018, 326470.

52. Li, B.; Dewey, C.N. RSEM: Accurate transcript quantification from RNA-Seq data with or without a reference genome. BMC Bioinform. 2011, 12, 323. [CrossRef]

53. Vivian, J.; Rao, A.; Nothaft, F.A.; Ketchum, C.; Armstrong, J.; Novak, A.M.; Pfeil, J.; Narkizian, J.; DeRan, A.D.; Musselman-Brown, A.; et al. Toil enables reproducible, open source, big biomedical data analyses. Nat. Biotechnol. 2017, 35, 314-316. [CrossRef] [PubMed]

54. Love, M.I.; Huber, W.; Anders, S. Moderated estimation of fold change and dispersion for RNA-seq data with DESeq2. Genome Boil. 2014, 15, 31. [CrossRef] [PubMed]

(C) 2020 by the authors. Licensee MDPI, Basel, Switzerland. This article is an open access article distributed under the terms and conditions of the Creative Commons Attribution (CC BY) license (http://creativecommons.org/licenses/by/4.0/). 